\title{
Situating Continuing Professional Development in Life Long Learning in
} Qatar

\author{
Vishanth Weerakkody ${ }^{1}$, Mohamad Osmani ${ }^{2}$, Paul Waller ${ }^{1}$, Nitham Hindi $^{2}$ \& Rajab Al-Esmail ${ }^{2}$ \\ ${ }^{1}$ College of Business Arts and Social Sciences Brunel University London Uxbridge, Middlesex, UK \\ ${ }^{2}$ College of Business and Economics Qatar University Al Tarfa, Doha 2713, Qatar \\ Correspondence: Mohamad Osmani, College of Business and Economics Qatar University Al Tarfa, Doha \\ 2713, Qatar. Tel: 974-4403-7725. E-mail: m.osmani@qu.edu.qa
}

Received: July 12, 2016

doi:10.5539/ijbm.v11n11p81
Accepted: September 12, 2016 Online Published: October 27, 2016

URL: http://dx.doi.org/10.5539/ijbm.v11n11p81

\begin{abstract}
Continued professional development (CPD) has been at the centre of capacity building in most successful organisations in western countries over the past few decades. Specialised professions in fields such as Accounting, Finance and ICT, to name but a few, are continuously evolving, which is necessitating certain standards to be followed through registration and certification by a designated authority (e.g. ACCA). Whilst most developed countries such as the UK and the US have well established frameworks for CPD for these professions, several developing nations, including Qatar (the chosen context for this article) are only just beginning to adopt these frameworks into their local contexts. However, the unique socio-cultural settings in such countries require these frameworks to be appropriately modified before they are adopted within the respective national context. The purpose of this paper is to examine the role of CPD in Qatar through comparing the UK as a benchmark and drawing corresponding and contrasting observations to formulate a roadmap towards developing a high level framework.
\end{abstract}

Keywords: CPD, life-long learning, accounting, ICT, Qatar

\section{Introduction}

According to Madden and Mitchell (1993), Continuous Professional Development (CPD) involves the maintenance and enhancement of knowledge, expertise and competence of professionals throughout their careers. CPD is seen as a source of competitive advantage for all modern organisations that have to operate in an increasingly global market and in dominant and dynamic fields such as ICT and finance this is something that cannot be addressed unless education shifts from a time-bound perspective to a lifelong learning one (McGuire et al., 2001). It is a well-known fact that learning is a process that never ends; as workers constantly face new complexity and are compelled to find innovative solutions. It is no longer possible to capture all the required knowledge during the undergraduate years or at the start of one's career and then spend the rest of the working life applying such knowledge (Megginson \& Whitaker, 2007).

The ever-growing complexity of industry and commerce together with advancements in ICT and globalization, highlights the need for a continuous learning process to support individuals as well as organizations in their socio-economic development (Moyle, 2010). Lifelong learning is defined as the "lifelong, voluntary, and self-motivated" pursuit of knowledge to respond to the evolving needs (CIA World Factbook, 2013). As such, it not only enhances social inclusion, active citizenship and personal development, but also competitiveness and employability. This, however, cannot be achieved without clear mapping of the strategy for translating the constant need for learning and development at personal and community levels. Individuals need to understand the need for continuous development whilst the community and professional bodies need to strive for keeping CPD abreast with the global evolution and nationally set priorities and needs. Therefore, a reference framework for lifelong learning should be put in place so as to ensure that each effort spent in this direction is valuable and brings benefit to both the individual that undergoes the process as well as to the society that supports such effort. Whilst this process needs to evolve along with market (national and international) needs and demands, the process needs to be monitored and certified in terms of quality and fitness for purpose. This requires a sustained effort to assess the gaps and challenges that and advances in knowledge and research into CPD, so as to be able to deliver a response that is focused and prompt even when taking into account the time needed for achieving the 
desired results.

Qatar, like other GCC countries, albeit less critically so, has a high proportion of youth. For example, Qatar has more than $30 \%$ of its population who are under 25 which is expected to increase (Al Munajjed \& Sabbagh, 2011). In such an environment, economic indicators are always cautiously optimistic as such a positive prospect should be accompanied by significant investments in education and youth development. In a survey conducted in 2011 (Al Munajjed \& Sabbagh, 2011), it is revealed that there is a significant lack of confidence in the future of these youths despite considerable investment by the government and the relative affluence of GCC countries, many youths feel disconnected from the wave of development; furthermore, in the report youths feel there is high level of unemployment (Al Munajjed \& Sabbagh, 2011). In the past decade, there has been a substantial increase in investment on education, which resulted in higher level of education attainment in both genders with Qatar taking a leading role in this regard. However, such an increase in educational attainment is not well reflected when looking at employment rates (Karoly, 2010). This is coupled by lower gender equality in the labour force, despite the rapid increase of females in attaining higher degrees (Rutledge et al., 2011). This goes to show the undercurrent skills gap in GCC countries (Qatar included). Adding to that the prospect of declining demand and/or falling prices and ultimately the depletion of gas and oil, requires a robust human capital development strategy to build a much more diversified and productive economy. Suffice to say that although this seemed to be a long-term strategic problem a few years ago, it is no longer the case now where the recent falling oil prices have forced Qatar to acknowledge it as an increasingly urgent problem. To this end, there needs to be a radical change to professional development policies and practices through education and closer engagement between industry (both private and public) and professional bodies in core domains. In this article we focus on accounting and finance and information and communication technology as exemplar fields. These fields are both strategically and operationally important for the development of a nation and therefore having in place a roadmap for CPD and LLL is of paramount importance for a developing economy such as Qatar. Whilst most developed countries such as the UK and US have well established frameworks for CPD across different industry sectors including accounting and finance and ICT, several developing nations have adopted these successfully into their local context. However, the unique socio-cultural settings in such countries require these frameworks to be appropriately modified before they are adopted within the respective national context. The purpose of this paper is to examine the role of CPD in Qatar through comparing the UK as a benchmark and drawing corresponding and contrasting observations to formulate a roadmap towards developing a high level framework.

In doing so, this paper aims to establish a roadmap towards a framework within which the CPD components of the Roadmap can be developed and adopted in Qatar. The context for doing that is "professionalism" and its perceived importance, professional standards and development in general, and the central role of CPD as a specific concept and development activity. The purpose of the framework is to separate out the professional development and CPD-related responsibilities and activities of the actors involved, and summarise their nature. This is necessary to avoid potential confusion between CPD as it relates to a profession and professional body, human resource management (HRM) support for professional development in a company or sector, and an individual professional: they interconnect but are distinct. Objectives and motivations for individuals, employers and professional institutions are different, sometimes in harmony, sometimes in conflict (Jones \& Robinson, 1997). This is particularly important in the Qatari context where the socio-cultural norms may a huge influence on how professional development practices are perceived and implemented in organisational contexts. Moreover, how CPD is perceived in the public sector (i.e. a government ministry or department) will be quite different to private sector (i.e. in an organisation with multinational links) in a country such as Qatar. Therefore, it is important to define CPD and contextualise it based on the local context when developing any roadmap.

To examine the arguments put forth above and to formulate the basis for a framework for CPD, the remaining sections of the paper are structured as follows. In the next section, a brief overview of the human capital development strategy in Qatar is offered explaining how CPD will contribute to this strategy. Next, a brief overview of professionalism and professional institutes are offered to set the context to CPD using the example of UK as a benchmark. Next, a discussion is offered of CPD, defining the concept and outlining the role of various professional institutes in the domains of accounting and finance, information and communication technology and human resource management, again using UK as an example. Thereafter, the role of employers in promoting and implementing CPD is examined followed by proposing the foundations for a Conceptual Framework to support CPD Components of a Life Long Learning Roadmap.

\section{Professionalism and Professional Development: Defining the Domain}

Prior to exploring the development of a continuous professional development framework, it is vitally important to understand the concept of profession and professionalism. This should enable us to understand the main 
building blocks of a professional development framework. This section, henceforth, provides an analytic discussion of the how professional standards have been preserved and developed for different professional bodies in their respective fields.

Setting aside the playing of sport as a paid job, the Merriam-Webster dictionary defines professionalism as the conduct, aims, or qualities that characterize or mark a profession or a professional person. This fits with the commonplace use of "professional" to mean someone who carries out a function to a high practical and ethical standard. However, in the workplace, profession and professional refer (according to the dictionary) to "a calling requiring specialized knowledge and often long and intensive academic preparation". There is extensive academic literature in the fields of sociology and management science on professionalism, professionalism and professionals (for example Carr-Saunders \& Wilson, 1933; Evetts, 2013; Lesser CS et al., 2010; Lynch, Surdyk, \& Eiser, 2004; Martimianakis, Maniate, \& Hodges, 2009; Martin, Foulonneau, Turki, \& Ihadjadene, 2013; Mills \& Larson, 1978; Noordegraaf, 2007; Spada, 2009; Van De Camp, Vernooij-Dassen, Grol, \& Bottema, 2004; Van Mook et al., 2009) but the focus in this paper is to develop a simple and practical framework, so it will work from the definition above, noting but not delving into this wider material.

The specific identification of such callings appears in the UK in the 19th century notably in the fields of medicine (the British Medical Association, BMA, was founded in 1832) and accountancy (Baker, 2014; Miranti, 2014); even earlier in the case of law (Mayali, 2010). Contemporaneously, there was the emergence of organisations of such specialists, like the BMA, the world's first professional body for engineers (the Institute of Civil engineers, founded 1818) the London Law Institution (now the Law Society) founded in 1823, and in accountancy in the 1870s (Walker, 2004). Membership of such groups was intended to convey assurance of standard of work and behaviour, and drive rogues from the trades - in so doing, creating a closed market for such professional services. These were the antecedents of today's professional institutes: membership bodies with subscriptions that normally set professional standards and require members to conform to a Code of Practice. Many have significant influence on national policy and legislation, representing the interests of their members.

Evolving over two centuries, it has become a requirement for a person to be registered or certified by a designated authority (a regulator) in order to practice in certain fields, particularly where there is a risk from malpractice to people's life, safety, liberty or wealth (such as medicine, law, and finance again, but also construction). The regulatory body may be different to or a separate function of a professional institute. For example, the General Medical Council in the UK was established by the Medical Act 1858 . There are 102 regulated professions in the UK meaning that to practice them a specific level of qualification, a licence or certificate, or registration with a legally authorised body is required by law. An unregulated occupation is one for which there is no such legal requirement.

It is normal for a nation to have one professional body (and if necessary a regulatory body) for a specialism: there is little competition between such bodies. Of course, members of the professions may work for organisations that do compete in the market. In the UK, for example, A Royal Charter may be endowed on a professional body to give it Chartered status and specific powers, including having Chartered members. Having a charter granted by the monarch carries the responsibility for the body to put the public interest before that of its members, and to submit to scrutiny by the Privy Council to ensure that it fulfills its responsibilities about maintaining the standing of its profession. Otherwise, an organization might have Institute status, awarded by the responsible minister in the government. More generally, either type will be an incorporated, non-profit organization.

Membership of the institutes will typically be at a number of levels with designations such as Student, Associate, Member, or Fellow, corresponding to a person's level of qualification and experience, with a threshold representing full qualification or readiness to practice. A professional title, such as Chartered, Fellow, or Registered, has been recognised as a symbol of status in the community. Certain titles, e.g. Chartered and Registered, are regulated under law and are awarded against set educational and experiential requirements by the professional body. They may be rescinded if criteria are not maintained. These protected titles are not solely tied to regulated professions.

In the UK accountancy is regulated but HRM and ICT are not. All have institutes with Chartered status: the Institutes of Chartered Accountants (in Scotland, founded in 1854, England and Wales, founded in 1880), the Association of Chartered Certified Accountants (global, founded 1904), the Chartered Institute of Personnel and Development (founded in 1913, receiving a Charter in 2000), and the British Computer Society (founded 1957, Chartered in 1984).

As these dates suggest, in the UK, accountancy is regarded as one of the "old" professions, whereas HRM and 
ICT are "new" ones. It was once a matter of debate as to whether the two new ones are really professions. In the early days of the computing industry (the 1950s and 1960s), it was unclear what the required standard was for someone to be a programmer (Ensmenger, 2001) with a variety of inconsistent approaches from employers, academia and professional societies (Finerman, 1975) leading to a lack of recognition of a defined status of professionalism. Indeed, with the widespread take-up of personal computers and office software, even the need for computing professionals was questioned in some quarters (Holmes, 2008). While having much earlier roots in personnel management, specialisms in HRM warranting professional qualifications emerged in the 1960s and 1970s (CIPD, 2015), leading to it and ICT (as skills such as software development and network management became better defined and business-critical) becoming recognised professions towards the end of the 20th century.

A direct implication of the term professional is that it is a quality of an individual, not of their employment as such. The professional institutes fulfil the role of supporting the development and maintenance of professional status of those individuals. At the very least, they set standards, verify the achievement and maintenance of those standards, and they frequently accredit training programmes and sometimes offer them themselves. A range of support materials in the form of guidelines, checklists, tools, and resources (e.g. libraries) will also be offered to members. Three types of professional standards are common:

- Education, qualifications and experience

- $\quad$ Ethical standards (through a Code of Conduct)

- Currency of knowledge

The last of these has a dynamic quality that the others do not: it constantly changes. Yet the expectation of a client or employer of a professional is that he or she is up to date with developments in the field (new tax rules, employment law, technical practice, or whatever). So professional institutes require that their members keep up to date in both knowledge and skills - that is, they continuously develop their professional capability. Institutes set the standards and processes for this activity, provide support and tools, and monitor its performance. This is "Continuing Professional Development" or CPD.

\section{Continuing Professional Development (CPD)}

In 1994, the Institute of Personnel and Development (IPD) defined CPD as "the conscious updating of a professional's knowledge and the improvement of personal competence throughout their working life" (Bailey, 2015). The rationale for this is that it is "the means by which the professions across the world ensure that their knowledge and skills remain up to date and relevant to changing needs and environments; CPD significantly contributes to the quality and reputation of the professions" (Friedman, 2013). Today, the CIPD puts it more personally: CPD is a combination of approaches, ideas, and techniques that will help individuals manage their own learning and growth (CIPD, 2016). This statement emphasises that it is the individual professionals that are responsible for their own development, supported by their Institute (Mann, 2004). Given that in the fields of accounting and ICT, many practitioners are either self-employed or contractors (less so in HR), which means that CPD is not confined to an employer-employee relationship but more importantly expanding to employees themselves as an independent entity (ITNOW, 2005). This may be a cause of misunderstanding amongst individual professionals. it is by no means certain that all either understand or have a positive attitude towards CPD (begging the question of how they keep up to date), or they see learning as limited to formal training and are not conscious of other learning opportunities (and therefore seen no benefit in reflecting on them or keeping a record - an essential component of CPD) (Bailey, 2015). Bailey also notes that in older professions (including currently accounting-ACCA), CPD might be measured by hours spent, but the norm nowadays is to require reflection on learning and assessment of impact on performance, which better accommodates a wider variety of informal learning activities such as reading, research, online browsing, coaching, being mentored, practice at work, listening to podcasts, watching videos, attending briefing meetings, and so on.

Whilst classroom learning continues to play a major part, the consensus today is that the leaning process, however informal, is become more explicit after graduation - in the place of work (HRMID, 2016) and indeed is popular (Rothwell \& Arnold, 2005). Experiential learning, i.e. learning by doing also contributes (Collin, Van der Heijden, \& Lewis, 2012). Particularly with the advent of online sources of learning, the nature of the learning is less explicit than with formal courses, making evaluation and recording harder to carry out (Little, 2009). However, digital learning resources are seemingly as increasingly useful (Hyland, 2009).

As well as being one provider of digital resources, professional institutes now facilitate a range of online support for their members' CPD, for example ACCA, BCS, and CIPD. These include their own requirements, but in the 
case of accountants, the International Federation of Accountants (IFAC) publishes a prescriptive standard for CPD in International Educational Standard 7 (IES 7). Whilst contributing to a more uniform standard internationally for professionals, a study of accountants in the Asia-Pacific region (De Lange, Jackling, \& Suwardy, 2015) found different perceptions of appropriateness of IES 7 between those in developing and developed economies, with shortcomings felt by those in the former areas suggesting more localisation was needed.

Taken together, these findings inform the construction of a CPD Roadmap by highlighting the need for ensuring that professionals and their employers in Qatar fully understand the nature of CPD, the rationale for it, the standards expected of them, the means by which learning can be done, the importance of reflection and recording, and the roles and resources of the relevant professional bodies.

\subsection{CPD Implementation Frameworks}

The discussion above has emphasised that the responsibility for CPD lies with the individual professional with support from a professional institute. However, the environment in terms of processes, resources and support provided by an employer is highly significant (Lambert, Vero, \& Zimmermann, 2012). In the UK, for example, it is commonplace for employers to have performance management and appraisal (PMA) processes. It is culturally acceptable, indeed expected, that managers in an organisation will individually or collectively judge an employee's performance and give feedback on it. It is an expectation that any employer other than the smallest will have a management process for at least giving feedback on performance. Lack of constructive feedback will be regarded by many employees as poor management practice. Most employers, certainly large public and private ones, will have a performance appraisal system that reflects on the preceding period and assesses how a person's performance has met up to expectations. It usually involves initial objective setting (using say a SMART set of objectives) followed up by a process of self and manager assessment against those objectives. A marking scheme may be used (e.g. one to five), and that may be absolute, or moderated within a group to be relative to peers. Rewards or sanctions may be attached to outcomes. In organisations with sophisticated HR capability, it may even provide data for workforce planning.

As part of, or in parallel with, PMA, organisations may operate a development planning process, requiring employees to create and carry out a personal development plan (PDP). The PDP will set out learning and development objectives, typically for the coming year. The scope may be (partially or wholly) related to the current job, related to progression within the organisation, or concerns a wider development. It is here that employers, where supporting a PDP for their professional employees, actively recognise and facilitate professional CPD. In the case of ACCA for accountants, the professional body may even approve (or otherwise) an employer's development programme as sufficient to meet its CPD standards. This has two potential outcomes: while increasing the worth and likely job satisfaction of the employee, it also increases his or her marketability to other employers (Dinger, Thatcher, Treadway, Stepina, \& Breland, 2015).

To support the PMA and PDP, an employer may develop (or adopt from a profession) one or more competency frameworks within its organisation, defining the set of duties or tasks performed as part of a job with the standards which should be achieved in these duties, including the behaviours, knowledge and actions expected at various levels of proficiency. Competency frameworks have become increasingly common (e.g. in the public sector) as HR departments seek to overlay structure to jobs to support management and employees. Such a framework may also be developed across a profession, by a professional body or, as in the case of ICT in the UK, by a third party.

The CIPD's Profession Map sets out the roles and outputs of HR professionals across all specialist areas of the profession-10 professional areas and eight behaviours - defining the expected activities, behaviour and knowledge applicable at four increasing levels of competence. It is intended to apply internationally to all sectors and types of organisation employing HR professionals (CIPD, 2012). CIPD HR professional map is portrayed in Figure 1. Band 1 in the CIPD HR map focussed on supporting colleagues with administration and processes helping to effectively manage information and data and is customer orientated; Band 2 advises on and/or manages HR related issues relating to an individual or a team and has a clear understanding of the evaluation process and the solutions available. Band 3 leads a professional area acting as a consultant or partner, addresses key HR challenges at an organisational level for the medium and long-term; and Band 4 leads and manages a professional area(s) and/or the organisation and will be responsible for developing and delivering organisational and HR strategy (CIPD, 2016) 


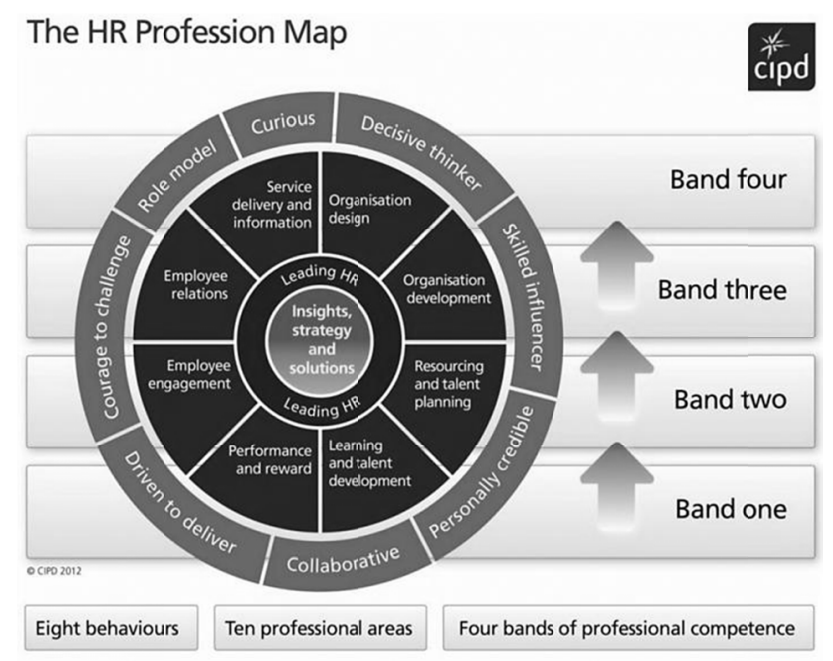

Figure 1. The HR professional map

Source: CIPD, 2012.

The equivalent for the ICT profession is the Skills Framework for the Information Age (SFIA) developed and maintained by the independent SFIA Foundation. "SFIA is a practical resource for people who manage or work in information systems-related roles of any type. It provides a common reference model in a two-dimensional framework consisting of skills on one axis and seven levels of responsibility on the other. It describes professional skills at various levels of competence. It also describes generic levels of responsibility, in terms of Autonomy, Influence, Complexity and Business Skills". It is available in English, German, Spanish, Arabic, Chinese, and Japanese. The BCS has developed a tool, SFIAPlus, for its members to help them navigate from SFIA to relevant training courses. Formally established in 2000, and regularly updated, SFIA has become the globally accepted common language for the skills and competencies required in the digital world (www.sfia-online.org).

SFIA is unique in defining skill levels in terms of increasing responsibility, rather than simply depth of expertise (www.sfia-online.org). Each level is described in detail that captures the degree of autonomy, influence, complexity and breadth of vision, all of which increase from lower to higher levels as outlined in Figure 2. The ACCA provides a similar competency framework and guide to qualifications for the accounting profession, covering 10 competency areas.

\begin{tabular}{|r|l|l|}
\hline Professional role & SFIA Levels of responsibility & \multicolumn{1}{c|}{ Organisational role } \\
\hline Practice Lead & $\begin{array}{l}\text { 7. Set strategy, Inspire, Mobilise } \\
\text { 6. Initiate, Influence }\end{array}$ & Senior Management \\
\hline Subject Specialist & 5. Ensure, Advice & First Line Management \\
\cline { 2 - 3 } Skilled Professional & 4. Enable & Team Leader \\
\hline On learning curve & 2. Assist & Experienced Team Member \\
\hline 1. Follow & On learning curve \\
\hline
\end{tabular}

Figure 2. Mapping of professional and organisational roles to levels of responsibility using SFIA framework

Skills or competency frameworks can underpin mapping by individuals, to assess their current position and CPD needs, or by organisations for job structuring and descriptions, skills gap analysis, and designing development streams for specific groups of professionals. They might also underpin a broader development programme for professionals where they form a large group of employees (or correspond to the main business of an employer, such as an accounting firm or ICT services company). An example of such, in a general but large employment 
sector, is the UK Government's ICT Capability Strategy (Cabinet Office, 2011). This set out a "Blueprint" showing career development paths for ICT profession in the public sector. Individuals entering the sector or aiming to progress to senior levels within it should thus "be able to see possible routes forward in their development, identify the skills and the experience they need to acquire and the standards they need to reach, and have access to the means to achieve their goals".

A key product created as part of that strategy was a map of career paths through the profession, relevant to that particular sector, and bringing the appropriate elements of the SFIA matrix. Career path models are based on elements of a skills or competency framework like SFIA and are designed to show individuals possible stages through which they might develop their careers in a particular area or a profession e.g. systems development in IT.

\section{The Context of Qatar in Human Capital Development and CPD}

Recent studies commissioned by the continuing education department at Qatar University shows that from an organisational perspective, to respond to the evolution of the work market, Qatar will need to have a comprehensive competencies reference framework for the analysis of existing gaps, clear job description (based on corporate needs and task analysis), and continuous development plans (Kardaman, 2010). While the government has stressed the importance of diversifying the economy and set out its vision for building a knowledge economy through a nationalisation programme (Qatarisation), already, there are signs that implementing this vision will be hugely challenging due to competency related issues as well as the socio-cultural influences that have shaped both the individual and organisational mind-sets. Indeed, Qatari organisations will need to reconsider their position on CPD if such vision is to be realised. With this, HRM practices in organisations will also need to be revisited including how job roles are designed, competencies needed for the roles are identified, appraised and developed, as well as how performance is assessed and training needs identified and facilitated, including from whom these needs are sources and associated professional accreditations and/or certificates obtained (Weerakkody et al., 2015). Most importantly, the CPD will need to take into account local context and both personal and corporate need by assessing them through evidence based research rather than simply be influenced by external trends or buzz-words (Kardaman, 2010).

To facilitate this, organisations such as the Qatar Chamber, Supreme Education Council, Qatar Foundation and NGOs involved in HCD as well as the general secretariat for planning \& development should be involved in the definition of overall competence frameworks as well as the specific ones for Information Communication Technologies (ICT), Finance and Accounting and Human Resources Management (HRM) that will best suit the needs and expectations of Qatar to meet its 2030 strategy (Kardaman, 2010). The Qatari national vision states that Qatar aims to increase the effective participation of its citizens/local labour force in the development of society and its positive evolution towards a reference example for the region and beyond (Qatar National Vision 2030, 2013). Qatar fosters and nurtures research in many critical aspects of science and is heavily investing in building a first class education, health and social context. This also requires a pathway to exploit research results from around the world both in terms of economy and in the education domain by constantly evaluating and refreshing skills and competencies. Thus, by drawing from established CPD standards, this paper aims at proposing a set of established good practices for professional development and lifelong learning in Qatar.

The National Development Strategy (2011-2016) stems from the national vision and its commitment to increasing the welfare of all Qatari citizens with one of the focal areas being the provision of the best education in a prosperous, stable and secure society (Qatar National Development Strategy 2011-2016, 2013). The 2011-2016 strategy aims at the progressive achievement of this transformation based on a set of priorities. For each of the vision pillars, the document provides a strategy for enabling concrete achievements. The framework proposed in this paper will support this strategy providing organisations, NGOs and policy-makers with a roadmap consisting of a set of programmes, methods and recommendations for evaluating and enhancing the skills and competencies of the present and future Qatari workforce.

\section{Components of Conceptual CPD Framework}

The preceding sections presented a set of theorised components for developing an effective CPD framework based on existing implementation using UK as an exemplar. This is followed by brief profile of the current status of human resource in the context of Qatar. This section brings together the themes of this paper into a summary table (see Table 1) that provides this framework and presents the building blocks of the CPD framework components in preparation to be localised in a Qatari context. The main purpose of the framework is to identify the professional development and CPD-related responsibilities and activities of the actors involved, so that paths within the Roadmap can be designed to define those and put them into operation. 
The actions outlined in Table 1 will need to be operationalised taking into account the local socio-cultural context and norms that may influence a particular organisation. In a Qatari context, the strong linkage between local culture and educational systems and the disconnect between job requisites and established CPD practices make it quite challenging to follow an organised path for professional development. This is further compounded by the lack of local-national skilled populations, which has dictated the direction of most GCC economies (Al-Masnad, 1999; Rose \& Doveston, 2015). The underdeveloped standards and guidelines to evaluate individuals' contribution at the workplace in terms of job-fit and behavioural competencies needed to perform effectively on the job are critical gaps found in most organisations in the Qatar (Weerakkody et al., 2015). Therefore, the framework needs to take into consideration best-fit in terms of professional bodies and standards to follow. A one-size-fits-all will not work in the Qatari context and therefore professional standards practiced in the UK or the US (i.e. for key fields such as accounting and ICT and indeed HR) may not work 'off the shelf' in Qatar and certainly need to be modified and adopted (Weerakkody et al., 2015).

Table 1. A conceptual framework to support CPD components

\begin{tabular}{|c|c|c|}
\hline Professional Institute & Employer & Individual Professional \\
\hline Provide a range of membership grades & $\begin{array}{l}\text { Operate a personal development system to } \\
\text { support organisational objectives }\end{array}$ & Join the relevant professional institute \\
\hline $\begin{array}{l}\text { Define qualifications required for } \\
\text { each grade }\end{array}$ & Support and encourage employees' CPD & $\begin{array}{l}\text { Register for the appropriate CPD scheme and } \\
\text { understand the requirements }\end{array}$ \\
\hline $\begin{array}{l}\text { Define CPD scheme and set } \\
\text { standards. Measures and rules }\end{array}$ & $\begin{array}{l}\text { Provide opportunities for training and other } \\
\text { learning and development }\end{array}$ & Set and record learning objectives \\
\hline Verify CPD completion & $\begin{array}{l}\text { Optional: run training/development } \\
\text { programmes in-house }\end{array}$ & $\begin{array}{l}\text { Undertake range of learning activities to meet } \\
\text { objectives and CPD requirements }\end{array}$ \\
\hline $\begin{array}{l}\text { Optional: provide courses and other } \\
\text { learning resources and opportunities }\end{array}$ & $\begin{array}{l}\text { Optional: develop career path models for } \\
\text { professionals in the organisation }\end{array}$ & $\begin{array}{l}\text { Reflect on and record learning for CPD record, } \\
\text { using any tools or templates provided by the } \\
\text { institute }\end{array}$ \\
\hline $\begin{array}{l}\text { Optional: provide tools for planning } \\
\text { and recording } \mathrm{CPD}\end{array}$ & $\begin{array}{l}\text { Optional: operate planned career } \\
\text { development programmes for subsets of } \\
\text { professionals }\end{array}$ & $\begin{array}{l}\text { Provide CPD record to professional institute as } \\
\text { required }\end{array}$ \\
\hline \multirow[t]{2}{*}{$\begin{array}{l}\text { Optional: provide competency/skills } \\
\text { framework }\end{array}$} & & $\begin{array}{l}\text { Fulfil employer's requirements and take part in } \\
\text { any training or development programmes } \\
\text { provided }\end{array}$ \\
\hline & & $\begin{array}{l}\text { Optional: use career path models or } \\
\text { skills/competency frameworks for career and } \\
\text { development planning }\end{array}$ \\
\hline
\end{tabular}

\subsection{Roadmap Development Methodological Framework}

Taking these considerations together with previous research (Weerakkody et al., 2015) into account, in Figure 3, we propose a high level methodological framework for situating continued professional education in life-long-learning in Qatar that is influence by professional practices in the UK for the field of accounting and ICT. This framework encapsulates in sequence the various activities that need to be undertaken to gather the required know-how and insights into identifying, localising and developing professional competencies relating to a specific field of specialisation, in this case Accounting and Finance and Information and Communication Technology, through Continued Professional Development. The country context, in this context Qatar, is a variable in Figure 3 and dictates the focus of the work undertaken from phase 5 onwards and therefore can be flexible based on where the CPD is implemented.

The LEARNER (A Life Long Learning Framework for Enhancing Graduate Attributes and Continuous Professional Development in Qatar) project is a 3-year research effort aimed at developing a Life Long Learning (LLL) Roadmap to facilitate the enhancement of Graduate Attributes and Continuous Professional Development (CPD) in Qatar based on national skills and competency requirements. The LEARNER Roadmap will encompass a comprehensive skills-development process including gap analysis and mapping of skills and competency requirements within the local and international job markets for specific roles (i.e. ICT, Accounting, and HR Management). These will be enhanced based on best practices and standards identified by international professional accreditation bodies. The LEARNER Roadmap will provide the necessary guidelines for policy and 
decision makers to monitor and actively engage in LLL and CPD activities.

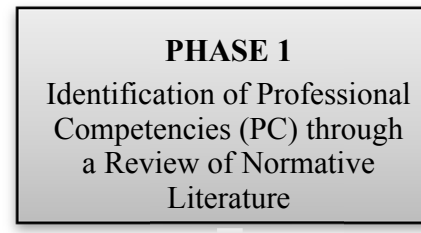

PHASE 2

Identification of $\mathrm{PC}$ through Horizon Scanning of State of the Art

\section{PHASE 3}

Analysis of Employer Needs

\section{PHASE 4}

Synthesise PC for Career Paths

\section{PHASE 5}

Conduct Localised Empirical studies to contextualise PC and identify Gaps

\section{PHASE 6}

Consolidate normative, secondary and empirical data for CPD Roadmap

\section{PHASE 7}

CPD Roadmap

Implementation and

Evaluation
1. Conduct Systematic Literature

Search

2. Conduct Focused Literature Search 3. Conduct Directed Literature Search

(focused on professions, e.g. accounting and/or ICT)

1. Review Government Policy \& Standards

2. Review Guidelines set by

Professional Bodies

3. Review Good practices from Industry

(focused on 'profession')

4. Scanning of Job market through review of recent vacancies

5. Stakeholder engagement with employers and professional bodies

(focused on 'profession')

1. Thematic analysis of normative and secondary data

2.Merge common themes to consolidate professional competencies

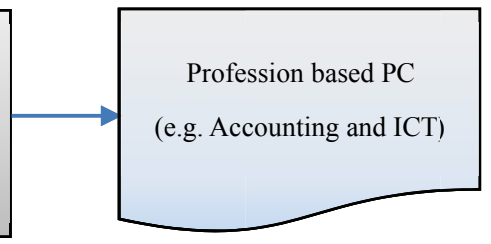

3. Gap analysis for professional career paths based on local needs in Qatar

4. Conceptualise gaps to identify best-fit localised strategies for bridging the Gaps

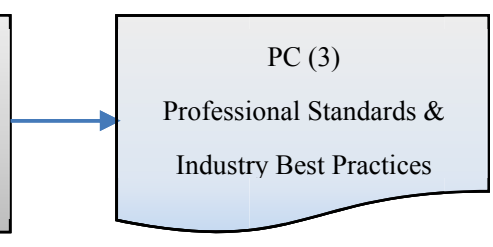

Professional Standards

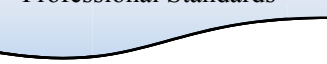

\section{PC (3)}

Standards \&

Industry Best Practices
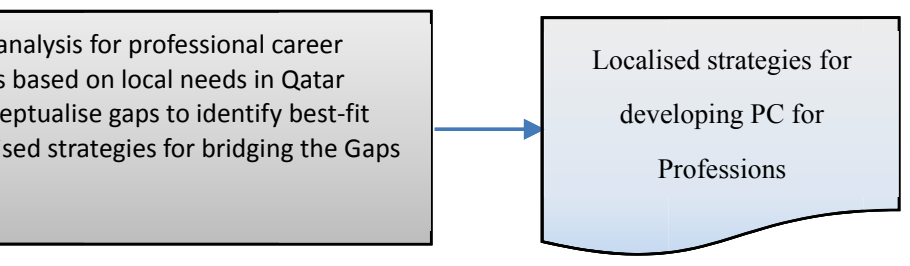

5. Formulate Localise CPD strategies and standards for Qatar

6. Identification of best-fit professional

bodies and/or chartered institutes

7. Develop Implementation Roadmap and

Evaluation criteria

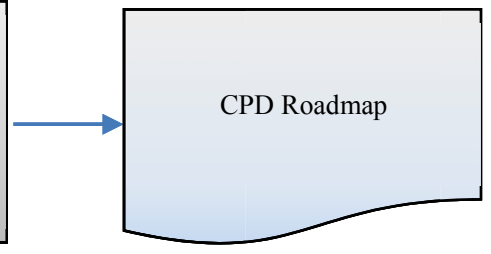

8. Develop Implementation Plans for CPD

Workshops

9.Perform Evaluation of Workshops

10. Identify action plans for evaluation

feedback

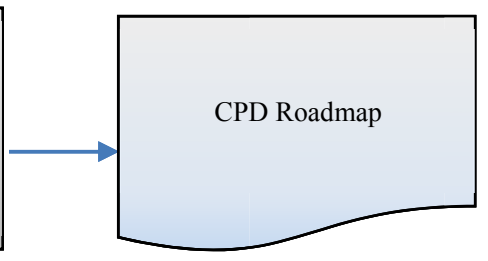

Figure 3. Methodological framework for developing a roadmap for CPD in Qatar 


\section{Analysis and Discussion}

A review of professional development practices in the UK reveals a structured process for CPD in important business and management professions such as accounting and ICT. The CPD processes are supported and facilitated by chartered bodies such as the Association for Chartered Certified Accountants (ACCA) and British Computer Society (BCS). Likewise, the professional development activities in the important profession of human resource management is supported and directed by the Chartered Institute of Personnel Development (CIPD) in the UK. These organisations set the standards for CPD in their respective professions and provide the mechanism by which standards in the professions are maintained and developed. From an employee's perspective CPD is encouraged and facilitated through membership of these professional bodies and typically span different tiers from student to fellow, corresponding to a person's level of qualification and experience. From an organisational or employer's perspective, the CPD frameworks followed by them will determine the direction of which professional bodies their employees are encouraged to follow. Irrespective, what is clear in the UK context is that CPD is encouraged and viewed as an essential part of the career advancement and journey for most professionals.

In a Qatari context, which is a developing economy that is aspiring to make rapid progress in development of human capital, the concept of CPD is only beginning to emerge in large private sector organisations such as banks and organisations with a multinational influence. Evidence from our ongoing research (Weerakkody et al., 2015) suggests that although there is much interest on CPD, the unique culture, history of trade and industry and the evolution of organisations, both public and private, pose major challenges in terms of changing the mind-set and awareness of organisations and people in Qatar. The fact that Qatar and indeed most other GCC countries are heavily reliant on expats to perform professional jobs in specialised fields such as accounting and ICT (Weerakkody et al., 2015) implies that the motivation for CPD at a national level has been low thus far. However, this position is now changing due to the nationalisation program launched in Qatar where emphasis is moving towards building a knowledge economy that is less reliant on oil and gas through diversification of investments and business across sectors. Nevertheless, the lack of standards and guidelines for CPD continues to create a void that is impeding this vision.

\section{Conclusions}

The aim of this paper was to establish a framework within which the CPD components of the LEARNER Roadmap can be developed, situating CPD in a central role as a specific concept and development activity. The framework proposed in this paper offers a roadmap to develop CPD within the broader context of life-long-learning in Qatar. This high level framework maps the key phases and activities that can be undertaken to draw from international standards and best practices and position then within the local context of Qatar and indeed any developing country context. Through this framework the authors posit that effective CPD strategies can only be developed and implemented by following a series of tasks which require comprehensive research and preparation to understand and position it within a local context. It is hoped that the framework and arguments presented in this paper offer policy makers, HR and senior managers in organisations several important challenges to consider as well as potential directions when developing CPD strategies. In addition, it offers professional bodies who wish to be involved and contribute to CPD in countries such as Qatar, important propositions to consider.

\section{Acknowledgement}

This paper was made possible by NPRP grant \# NPRP 7-1534-5-231 from the Qatar National Research Fund (a member of Qatar Foundation). The statements made herein are solely the responsibility of the author(s).

\section{References}

Al Munajjed, M., \& Sabbagh, K. (2011). Youth in GCC Countries-Meeting the Challenge. Riyadh: Booz \& Company Ideation Center.

Al-Masnad, L. (1999). Al amalah alwataniya wa dawruhah fi altanmiya alsina'ya fi dowal majlis alta'awun (The role of national labor in industrial development in GCC: The present and the future). In Seventh Industrial Conference in the GCC countries organized by The Gulf Organization for Industrial Consultations, in Doha.

Bailey, M. (2015). Professional development of HR practitioners-a phenomenographic study. European Journal of Training and Development, 39(3), 220-238. http://dx.doi.org/10.1108/EJTD-08-2014-0057

Baker, C. R. (2014). A comparative analysis of the development of the auditing profession in the United Kingdom and France. Accounting History, 19(1-2), 97-114. http://dx.doi.org/10.1177/1032373213513555 
Cabinet Office. (2011). Government ICT Capability Strategy. London, UK.

Carr-Saunders, A. M., \& Wilson, P. (1933). The Professions. Oxford University Press.

Chartered Institute of Personnel and Development (CIPD). (2015). History of HR and the CIPD, CIPD, London, Retrieved from http://www.cipd.co.uk/hr-resources/factsheets/history-hr-cipd.aspx

Chartered Institute of Personnel and Development (CIPD). (2016). What is CPD? CIPD, London. Retrieved from http://www.cipd.co.uk/cpd/about.aspx

CIA World Factbook. (2013). Retrieved from http://www.cia.gov/library/publications/the-world-factbook/

Collin, K., Van der Heijden, B., \& Lewis, P. (2012). Continuing professional development. International Journal of Training and Development, 16(3), 155-163. http://dx.doi.org/10.1111/j.1468-2419.2012.00410.x

De Lange, P., Jackling, B., \& Suwardy, T. (2015). Continuing Professional Development in the Accounting Profession: Practices and Perceptions from the Asia Pacific Region. Accounting Education, 24(1), 41-56. http://dx.doi.org/10.1080/09639284.2014.1002800

Dinger, M., Thatcher, J. B., Treadway, D., Stepina, L., \& Breland, J. (2015). Does Professionalism Matter in the IT Workforce? An Empirical Examination of IT Professionals. Journal of the Association for Information Systems, 16(4), 281-313.

Ensmenger, N. L. (2001). The "question of professionalism" in the computer fields. IEEE Annals of the History of Computing, 23(4), 56-74. Retrieved from http://ieeexplore.ieee.org/lpdocs/epic03/wrapper.htm?arnumber=969964

Evetts, J. (2013). Professionalism: Value and ideology. Current Sociology, 61(5-6), 778-796. Retrieved from http://csi.sagepub.com/cgi/doi/10.1177/0011392113479316

Finerman, A. (1975). Professionalism in the computing field. Communications of the ACM. http://dx.doi.org/10.1145/360569.360578

Friedman, A. L. (2013). Continuing professional development: Lifelong learning of millions. Taylor and Francis. http://dx.doi.org/10.4324/9780203806166

Holmes, N. (2008). The History of the Computing Profession. Computer, 41(1), 112-111. http://dx.doi.org/10.1109/MC.2008.30

HRMID. (2016). How HR practitioners must keep on learning. Human Resource Management International Digest, 24(1), 21-23. http://dx.doi.org/10.1108/HRMID-10-2015-0161

Hyland, L. (2009). Move aside CPD UPS is on its way. Training Journal, (June), 36-39.

ITNOW. (2005). The value of continuing professional development. ITNOW, 47(3), 21. http://dx.doi.org/10.1093/itnow/bwi054

Jones, N., \& Robinson, G. (1997). Do organizations manage continuing professional development? Journal of Management Development, 16(3), 197-207. http://doi.org/10.1108/02621719710164346

Kardaman, T.A., (2010). Self-Study Report for Administrative Unit Review (ADUR). Office of Continuing Education, Qatar University.

Karoly, L.A. (2010). The role of education in preparing graduates for the labor market in the GCC countries. Conference paper prepared for the 15th annual conference of the Emirates Center for Strategic Studies and Research on 'Education and the Requirements of the GCC Labor Market'. Abu Dhabi, United Arab Emirates, 1-3 February.

Lambert, M., Vero, J., \& Zimmermann, B. (2012). Vocational training and professional development: A capability perspective. International Journal of Training and Development, 16(3), 164-182. http://dx.doi.org/10.1111/j.1468-2419.2012.00402.x

Lesser, C. S., Lucey, C. R., Egener, B., Braddock, C. H., Linas, S. L., \& Levinson, W. (2010). A behavioral and systems view of professionalism. JAMA, 304(24), 2732-2737. http://doi.org/10.1001/jama.2010.1864

Little, B. (2009). The changing face of CPD. Training Journal, (June), 51-54.

Lynch, D. C., Surdyk, P. M., \& Eiser, A. R. (2004). Assessing professionalism: A review of the literature. Medical Teacher, 26(4), 366-373. http://doi.org/10.1080/01421590410001696434

Madden, C. A., \& Mitchell, V. A. (1993). Professions, Standards and Competence: A Survey of Continuing Education for the Professions. University of Bristol. 
Mann, S. (2004). Learning for a Lifetime. Professional Manager, 13(2), 28-29.

Martimianakis, M. A., Maniate, J. M., \& Hodges, B. D. (2009). Sociological interpretations of professionalism. Medical Education, 43(9), 829-837. http://dx.doi.org/10.1111/j.1365-2923.2009.03408.x

Martin, S., Foulonneau, M., Turki, S., \& Ihadjadene, M. (2013). Risk Analysis to Overcome Barriers to Open Data. Electronic Journal of E-Government, 11, 348-359.

Mayali, L. (2010). The Medieval Origins of the Legal Profession. Law and History Review, 28(1), 251-252. Retrieved

from http://search.ebscohost.com/login.aspx?direct=true\&db=brd\&AN=502147864\&site=ehost-live\&scope=cite

McGuire, D., Garavan, T. N., O'Donnell, D., \& Murphy, C. (2001). Continuing Professional Development in the Irish Legal Profession: An Exploratory Study. Continuing Professional Development, 4(2), 21-46.

Megginson, D., \& Whitaker, V. (2007). Continuing Professional Development (2nd ed.). Published by the CIPD, UK.

Mills, D. L., \& Larson, M. S. (1978). The Rise of Professionalism: A Sociological Analysis. Contemporary Sociology.

Miranti, P. (2014). The emergence of accounting as a global profession-an introduction. Accounting History, 19(1-2), 3-11. http://doi.org/10.1177/1032373213519750

Moyle, K. (2010). Building Innovation: Learning with technologies, Australian Council For Educational Research. Retrieved from http://research.acer.edu.au/cgi/viewcontent.cgi?article=1009\&context=aer

Noordegraaf, M. (2007). From "Pure" to "Hybrid" Professionalism: Present-Day Professionalism in Ambiguous Public Domains. Administration \& Society, 39(6), 761-785.

Qatar National Development Strategy 2011-2016. (2013). Retrieved from http://www.gsdp.gov.qa/portal/page/portal/gsdp_en/knowledge_center/Tab/NDS_ENGLISH_SUMMARY.p $\mathrm{df}$

Qatar National Vision $2030 \quad$ (2013). $\quad$ Retrieved from http://www.gsdp.gov.qa/portal/page/portal/gsdp_en/qatar_national_vision/qnv_2030_document/QNV2030_ English_v2.pdf

Rose, R., \& Doveston, M. (2015). Collaboration across cultures: Planning and delivering professional development for inclusive education in India. Support for Learning, 30(3), 177-191.

Rothwell, A., \& Arnold, J. (2005). How HR professionals rate "continuing professional development. Human Resource Management Journal, 15(3), 18-32.

Rutledge, E. J., Al-Shamsi, F., Bassioni, Y., \& Al-Sheikh, H. (2011). Women, Labour Market Nationalisation Policies and Human Resource Development in the Arab Gulf States. Human Resource Development International, 14(2), 183-193.

Spada. (2009). British Professions Today: the state of the sector. Retrieved from http://www.spada.co.uk

Van De Camp, K., Vernooij-Dassen, M. J. F. J., Grol, R. P. T. M., \& Bottema, B. J. A. M. (2004). How to conceptualize professionalism: A qualitative study. Medical Teacher, 26(8), 696-702. http://dx.doi.org/10.1080/01421590400019518

Van Mook, W. N. K. A., De Grave, W. S., Wass, V., O’Sullivan, H., Zwaveling, J. H., Schuwirth, L. W., \& Van Der Vleuten, C. P. M. (2009). Professionalism: Evolution of the concept. European Journal of Internal Medicine, 20(4), 81-84. http://dx.doi.org/10.1016/j.ejim.2008.10.005

Walker, S. P. (2004). The genesis of professional organisation in English accountancy. Accounting, Organizations and Society, 29, 127-156. Retrieved from http://www.elsevier.com/locate/aos

Weerakkody, V., Al-Esmail, R., Hindi, N. H., Osmani, M., Irani, Z., \& Eldabi, T. (2015). Localising Professional Skills Development Strategies in the GCC: Research and Policy Considerations for Qatar. International Journal of Humanities and Social Science, 5(9), 133-140. 


\section{Copyrights}

Copyright for this article is retained by the author(s), with first publication rights granted to the journal.

This is an open-access article distributed under the terms and conditions of the Creative Commons Attribution license (http://creativecommons.org/licenses/by/4.0/). 